MSD). MG was suspected and this diagnosis was confirmed by positive prostigmine test and typical electromyographic findings. Antibodies to acetylcholine receptors were not detected. The patient underwent thymectomy in Mars 1996. Then, under oral anticholinesterase therapy and corticosteroids $(60 \mathrm{mg}$ of prednisone daily), her condition stabilised, but her clinical status worsened when the dose of prednisone was tapered under $20 \mathrm{mg}$ daily. She finally improved after institution of ciclosporine (5 $\mathrm{mg} / \mathrm{Kg} /$ daily) in association with steroid therapy.

Results

Conclusion

\section{FRI0249 CORRELATION BETWEEN SERUM MUSCLE ENZYMES, MUSCLE WEAKNESS AND MUSCLE PATHOLOGY IN PATIENTS WITH POLYMYOSITIS}

${ }^{1} \mathrm{~W}$ Louthrenoo, ${ }^{1} \mathrm{~N}$ Weerayutwattana, ${ }^{2} \mathrm{~N}$ Lertprasertsuke, ${ }^{1} \mathrm{~W}$ Sukitawut. ${ }^{1}$ Division of Rheumatology, Department of Medicine; ${ }^{2}$ Department of Pathology, Faculty of Medicine, Chiang Mai University, Chiang Mai, Thailand

\subsection{6/annrheumdis-2001.570}

Background Polymyositis (PM) is a chronic inflammatory myopathy of unclear aetiology. Clinical features of PM have been well described, but the study of the correlation between serum muscle enzymes, muscle weakness and muscle pathology is limited.

Objectives We reported the clinical correlation between serum muscle enzymes, muscle weakness and muscle pathology in Thai patients with PM.

Methods A retrospective chart review was carried out in patients with PM, age $>16$, who had muscle biopsy available for review, and seen during January 1986 - December 1999. The diagnosis of PM followed Bohan and Peter's criteria. The degree of muscle weakness was graded $0-5$. The degree of muscle inflammation was scored $0-4(0 \%, 1-10 \%, 11-25 \%, 26-50 \%$ and $>50 \%$ of inflammatory cell infiltration, respectively), and the degree of muscle destruction was scored $0-4(0 \%, 1-10 \%, 11-25 \%, 26-$ $50 \%$ and $>50 \%$ of muscle fibre destruction respectively). Serum muscle enzymes including CPK, LDH and AST, which determined within 7 days prior to muscle biopsy, were used for analysis.

Results Of 163 patients, 123 had muscle biopsy performed. Only 102 specimens were available for review, of which 2 that showed granulomatous myositis were excluded due to the possibility of tuberculous myositis. Therefore, 100 charts were included for analysis. There were 22 males and 78 females, with their mean \pm SD age and duration of disease of $45.0 \pm 13.9$ years and $6.3 \pm 13.4$ months, respectively. The clinical diagnoses were idiopathic PM in 37 cases, idiopathic dermatomyositis in 13, myositis associated with malignancy in 5, and PM associated with connective tissue disease in 45 (SLE in 16 cases, scleroderma in 22, MCTD in 6 , and PAN in 1). The mean \pm SD scores of proximal muscle weakness, muscle inflammation and destruction were $3.2 \pm 0.8,1.5 \pm 1.6$ and $2.2 \pm 1.7$, respectively. Serum muscle enzymes including CPK, LDH and AST were elevated in $87 \%, 92 \%$ and $82 \%$, respectively, with a mean \pm SD level of 2,352 $\pm 3,239 \mathrm{U} / \mathrm{L}, 750 \pm 420 \mathrm{U} / \mathrm{L}$ and $196 \pm$ 193 U/L, respectively. Seventy-six percent had abnormal EMG findings that were compatible with myositis. There was a good correlation between the level of serum muscle enzymes and the degree of muscle inflammation and destruction $(p<0.02)$. The degree of weakness correlated well with the degree of muscle inflammation and destruction $(\mathrm{p}<0.05$ and $<0.01$, respectively). There was no significant correlation between ESR and serum muscle enzymes, muscle weakness or muscle pathology. Patients with idiopathic PM had more severe muscle pathology than patients with PM associated with connective tissue disease.

Conclusion Serum muscle enzymes showed a good correlation with muscle pathology. The degree of muscle weakness correlated well with the degree of muscle destruction. ESR had a limited value in patients with PM.

\section{FRI0245 CLINICAL COURSE AND OUTCOME IN MIXED CONNECTIVE TISSUE DISEASE}

A Georgiadis, D Bougias, PV Voulgari, AA Drosos. Division of Rheumatology, Department of Internal Medicine, Medical School, University of loannina, Ioannina, Greece

\subsection{6/annrheumdis-2001.571}

\section{Background}

Objectives To investigate the clinical course and outcome of patients diagnosed with mixed connective tissue disease (MCTD).

Methods Since 1981, forty-four patients with MCTD have been diagnosed and followed up until December 2000. We reevaluated all these patients by entering the demographic, clinical, laboratory, radiological and therapeutic disease characteristics in a database.

Results Thirty-nine patients had the typical feature of MCTD, 3 developed diffuse systemic sclerosis and 2 systemic lupus erythematosus. Thirty-six were female and 3 male. The mean age was 51.6 (11), the disease duration was 12.9 (5.2) (range 1-25 years) and the mean follow up was 6.6 (4.9) (range 1-19 years). Almost all patients $(95 \%)$ presented symptoms and signs of Raynaud's phenomenon, arthritis and arthralgias evolving the small joints of the hands. Pulmonary dysfunction was observed in $44 \%$, while pulmonary hypertension and renal involvement in 5\% of patients. All patients had positive U1Sn-RNP antibodies and high titers of antinuclear antibodies. Only $10 \%$ of our patients also had Ro (SSA) antibodies.

Conclusion It seems that our patients presented the typical clinical and serological features of MCTD. The majority of our patients had favorable outcomes, with pulmonary dysfunction being the most frequent, while pulmonary hypertension and renal involvement was observed in only a few cases.

\section{FRI0251 MUSCULOSKELETAL DISORDERS OF THE UPPER LIMB AND WORKRELATED FACTORS}

${ }^{1} \mathrm{M}$ De la Hera, ${ }^{2} \mathrm{M}$ Gandarillas. ${ }^{1}$ Medical Services, ENSA, Maliaño; ${ }^{2}$ Medical Services, ASTANDER, Astillero, Spain

\subsection{6/annrheumdis-2001.572}

\section{Background}

Objectives To study the association between upper extremity physical requirements (UEPR) at workplace and soft tissue lessions.

Methods A retrospective analysis (from 1-01-95 to 31-12-99) was carried out comparing temporal disability due to lateral, medial epicondylitis (LE), (ME) and shoulder tendinitis (ST) in two factories with different UEPR: a shipyard of 305 workers (AS) with high UEPR and a nuclear components manufacturing plant of 405 workers (EN) with low/medium UEPR. The UEPR 
were estimated by the investigators, as low, medium and high according to the repetitive and force work in the upper extremity.

Results All patients were male. Median age was 49 years (range: 33 to 52 ) in AS and 51 (25 to 60 ) in EN. Nineteen $(6,2 \%)$ cases were diagnosed in AS (10 ST, $8 \mathrm{LE}$ and $1 \mathrm{ME}$ ), and only 9 $(2,2 \%)$ in EN (7 ST and $2 \mathrm{LE})(\mathrm{p}=0.009)$. The cases were classified according to the factory and to the level of UEPR as follow:

AS/EN Low (2/5) Medium (6/3) High (11/1).

Annual and cummulative (95-99) risk proportion (\%) were (see Table 1):

An association between the type of factory (EN or AS) and the level of UEPR was observed, being the latter higher in AS ( $p$ $=0.04$ ). Relative risk of suffering LE, ME and ST was 2.8 (IC95: 1,3-6,1) in AS. Dominant side was affected in most cases $22(79 \%),(\mathrm{p}=0.002)$.

\begin{tabular}{lllllll}
\multicolumn{6}{l}{ Abstract FRI0251 Table 1} \\
\hline & 1995 & 1996 & 1997 & 1998 & 1999 & $95-99$ \\
\hline AS & 0.96 & 2.33 & 1.03 & 1.43 & 0.74 & 6.33 \\
EN & 0.66 & 0.24 & 0.50 & 0.21 & 0.39 & 1.96 \\
\hline
\end{tabular}

Conclusion Our data suggest that tasks with high UEPR have a relevant role in soft tissue lessions of the upper extremity and they are more frequent in the dominant side.

\section{FRI0252 EOSINOPHILIC MYOSITIS ASSOCIATED WITH BEHCET'S DISEASE}

B Coleiro, C Mallia. Department of Medicine, St Luke's Hospital, Pieta, Malta

10.1136/annrheumdis-2001.573

Behcet's disease, a systemic vasculitis of unknown aetiology, has a variety of clinical manifestations, the commoner ones including recurrent oro-genital ulceration, uveitis and rashes. Muscular involvement is an uncommon clinical feature and a review of the literature by Worthmann $\mathrm{F}$ et al. ${ }^{1}$ suggests that the myositis passes through two different stages of inflammation: a granulocytic-monocytic phase followed by a predominantly lymphocytic infiltration phase. We present the case of a 24 year old male who satisfies the International Study Group criteria for the diagnosis of Behcet's disease, ${ }^{2}$ and who developed features of a localised myositis which differs from that described in the literature in that, histologically, the inflammatory cell infiltrate included significant eosinophilia.

\section{REFERENCES}

1 Worthmann $F$, et al. Muscular involvement in Behcet's disease: Case report and review of the literature. Neurosci Disord. 1996:6(4):247-53

2 International Study Group for Behcet's Disease. Criteria for diagnosis of Behcet's disease. Lancet 1990:335:1078-80

\section{FRI0253 EOSINOPHILIC FASCIITIS: RETROSPECTIVE EVALUATION OF 7 CASES}

E Tunc, V Inal, G Keser, T Pirildar, T Türk, K Aksu, Y Kabasakal, F Oksel, E Doganavsargil. Rheumatology, Ege University Medical Faculty, Izmir, Turkey
Background Eosinophilic fasciitis (EF) is a rare disorder characterised by scleroderma-like enduration of the skin, predominantly on the extremities and peripheral eosinophilia. Absence of Raynaud's phenomenon and visceral involvement are typical features. Histologic findings include fibrosis of muscle fascia and eosinophilic infiltration. Different clinical entities are reported in association with EF. Hereby, we aimed to present clinical characteristics of our cases.

Objectives The medical data of 7 patients with EF (F/M:4/3; mean age $41.7 \pm 19$ ), who were followed up for $22.7 \pm 19.6$ months in Ege University Rheumatology department between January 1996 and December 2000. Mean disease duration was $11 \pm 9.2$ months on initial diagnosis. The diagnosis was made by en-block biopsy. Skin enduration was located on the lower and upper extremities in all cases. In one patient there was additional enduration on trunk. All cases had peripheral eosinophilia and hypergammaglobulinemia. Elevated muscle enzymes were present only in one case. High titer ANA positivity was present only in three female cases. 2 cases had carpal tunnel syndrome, one had interstitial eosinophilic pneumonia, one had pericarditis and Hashimato thyroiditis, one had vitiligo, one had type II DM which began simultaneously and one had psoriasis in association with EF. There were no history of any relevant medication and toxic material ingestion. No one had malignancy in the followup period.

Initial treatment consisted of methylprednisolone $(32 \mathrm{mg} /$ day $)$ and methotrexate $(10 \mathrm{mg} /$ week). Since in literature, high serum histamin levels and good response to $\mathrm{H} 2$ blockers were reported, ranitidine was also added to this treatment1. All the patients responded well; however one case was resistant to this treatment. D-penicillamine $(150 \mathrm{mg} /$ day $)$ and colchicine $(1 \mathrm{mg} / \mathrm{day})$ treatment were added for this patient. Skin endurations regressed in all cases. Two patient had complete and the other five had partial remission.

Methods

Results

Conclusion In conclusion, the diagnosis of EF should be always confirmed by en-block biopsy and presence of associated autoimmune pathologies should be kept in mind and searched. Malignancy should always be excluded. Response to appropriate treatment is generally satisfactory.

\section{REFERENCE}

1 Naschitz JE, Boss JH, Misselevich I, Yesfurun D, Rosner I. The fasciitis-panniculitis syndromes. Clinical and pathologic features. Medicine (Baltimore) 1996;75(1):616

\section{FRI0254 CHURG-STRAUSS SYNDROME (CSS) IN A SERIES OF 14 PATIENTS: A TWELVE YEARS EXPERIENCE}

J Mazzotti, G Riccio, E Venegoni, P Bottero. Uo Medicine, Section of Immunology, "G. Fornaroli" Hospital, Magenta (Milan), Italy

10.1136/annrheumdis-2001.575

Background Between 1988 and 200014 patients affected by CSS have been followed. Our series included 9 females and 5 males, the mean age at the diagnosis was 54 years (range 2178 ), the mean follow up period was 95 months (range 60-141). Four criteria were simultaneneously satisfied in all patients at the diagnosis, according to the vasculitis ACR classification. The most important clinical manifestations exept for asthma, eosinophilia and paranasal sinus abnormality costantly present, were arthralgias, cutaneous nodules, peripheral neuropathy. Renal and 